\title{
FAKTOR-FAKTOR PENDORONG PENYEBAB TERJADINYA KEMACETAN \\ Studi Kasus : Kawasan Sukun Banyumanik Kota Semarang
}

\author{
Iwan Wijanarko"), Mohammad Agung Ridlo ${ }^{2)}$ \\ Program Studi Perencanaan Wilayah dan Kota Universitas Islam Sultan Agung Semarang ${ }^{1,2}$
}

\begin{abstract}
Sukun region located in the southern city of Semarang is an activity node meetings between Semarang Upper and Lower part. In addition to the node activity, regional transport node Sukun is also because of the intersection between Setia Budi roads and highways. The rapid growth of traffic is felt at Setia Budi roads, this is because of the way as the initial point of entry into the city of Semarang from the south ( Yogyakarta - Solo ) both vehicles are going to Semarang and the entrance to the highway with a wide range of purposes. And trading activity and the presence of onsite services that are in the area resulted in increased activities of road users, the incidence of traffic generation and the high side barriers, which at certain hours of congestion and delays often occur. The research methodology used in this research is by using Deductive Quantitative Methods Rationalistic. With the technique of factor analysis and analysis of transportation, so it can be determined Level Of Service and factors - factors driving the cause of congestion in the area Sukun Banyumanik. The final results obtained from the analysis of the factors driving the causes of congestion on area Sukun is that congestion is due to the on site activity, the high capacity of the road, next to the barrier height and geometric conditions of the road.
\end{abstract}

Keywords : Transport, Service, Congestion

\begin{abstract}
ABSTRAK
Kawasan Sukun berada di sebelah selatan Kota Semarang yang merupakan simpul pertemuan aktivitas antara Semarang Bagian Atas dan Semarang Bagian Bawah. Selain sebagai simpul aktivitas, kawasan Sukun juga merupakan simpul transportasi karena adanya persimpangan antara Jalan Setia Budi dan Jalan Tol. Pesatnya pertumbuhan lalu lintas sangat dirasakan pada ruas Jalan Setia Budi, hal ini karena jalan tersebut sebagai tempat awal masuk ke Kota Semarang dari arah Selatan (Yogyakarta - Solo) baik kendaraan yang akan ke Kota Semarang maupun yang masuk ke jalan tol dengan berbagai tujuan. Dan adanya on site activity perdagangan dan jasa yang berada pada kawasan tersebut mengakibatkan meningkatnya aktifitas pengguna jalan, timbulnya bangkitan lalu lintas dan tingginya hambatan samping, dimana pada jam-jam tertentu sering terjadi kemacetan dan tundaan. Metodologi penelitian yang digunakan pada penelitian ini yaitu dengan menggunakan Metode Deduktif Kuantitatif Rasionalistik. Dengan teknik analisis faktor dan analisis transportasi, sehingga dapat diketahui Tingkat Pelayanan Jalan dan faktor faktor pendorong penyebab terjadinya kemacetan di Kawasan Sukun Banyumanik. Hasil akhir yang didapat dari analisis faktor-faktor pendorong penyebab terjadinya kemacetan pada Kawasan Sukun adalah bahwa kemacetan terjadi karena adanya on site activity, tingginya kapasitas jalan, tingginya hambatan samping dan kondisi geometrik jalan.
\end{abstract}

Kata kunci : Transportasi, Pelayanan, Kemacetan. 


\section{PENDAHULUAN}

Transportasi merupakan salah satu bagian terpenting di kehidupan manusia. Transportasi memiliki peran yang sangat besar di beberapa aspek kehidupan manusia, seperti aspek ekonomi, aspek lingkungan, aspek sosial, aspek pertahanan dan keamanan. Hubungan transportasi dan manusia erat kaitannya dengan lokasi kegiatan manusia, benda atau barang maupun kaitannya dengan jasa. Oleh karena peran transportasi sangat penting bagi kehidupan manusia, maka perkembangan transportasi menjadi suatu hal sangat penting. Transportasi sebagai alat penunjang dan penggerak dinamika pembangunan, dikarenakan transportasi juga katalisator dalam meningkatkan pertumbuhan ekonomi dan perkembangan wilayah (Timboeleng A. James, Kaseke H. Oscar, 2015). Pembangunanpembangunan sudah menjadi fokus utama pemerintah di suatu wialayah. Seiring dengan berjalannya waktu, kota menjadi lokasi yang penting dan strategis karena memiliki tarikan yang kuat bagi penduduk yang berada di luar kota tersebut (Ekawati Niken Natalia, Soeaidy Saleh Mochammad, Ribawanto Heru, 2014).

Kebutuhan manusia akan sumber daya, terutama sumber daya yang berada tersebar di suatu wilayah memunculkan pergerakan dan perpindah manusia yang didorong oleh kebutuhan manusia akan sumber daya disuatu tempat. Hal ini menunjukkan bahwa pergerakan manusia merupakan suatu kebutuhan pada kehidupan manusia (Warpani, 1990).

Meningkat cepatnya pertumbuhan pergerakan orang dan barang, membuat permintaan penyediaan jaringan jalan dari aspek kualitas dan kuantitas perlu ditingkatkan guna menampung segala pertumbuhan pergerakan tersebut. Namun hal yang muncul adalah kebutuhan transportasi (demand) lebih besar dari prasarana transportasi yang tersedia (supply) (Siswanto Agus, Putro Saptono, Tjahyono Heri, 2012).

Kota menurut konteks perencanaan sistem transportasi regional maupun nasional mempunyai fungsi sebagai simpul jasa distribusi yang memiliki peran dominan dalam hal pemacu tingkat pertumbuhan ekonomi. Adanya perpindahan barang dan manusia yang semakin komplek seiring dengan perkembangan kota mengakibatkan adanya sistem transportasi. Perpindahan barang ataupun manusia ini dapat menggunakan transportasi baik jarak pendek atau jarang jauh sekalipun (Tamin, 1997).

Proses aktifitas transportasi harus ada beberapa hal diantaranya:

1. muatan (barang/orang) sebagai objek yang diangkut dengan tujuan dipindahkan dari suatu tempat ke tempat yang lain, 
2. Kendaraan sebagai Pengangkut

3. Jalan yang dapat dilintasi oleh kendaraan dalam mengangkut objek

Terletak disisi selatan perbatasan Kota Semarang, kawasan sukun menjadi simpul pertemuan lalu lintas untuk Semarang bagian atas dan Semarang bagian bawah, menjadi simpul lalu lintas yang menghantarkan kendaraan untuk dapat langsung ke perbatasan atau pinggiran dengan tidak melewati dalam perkotaan. Menjadi simpul untuk transportasi Jalan Setiabudi dan Jalan Tol, sehingga pada jam puncak akan mengalami kemacetan ataupun tundaan. Sehingga tujuan dari penyusunan penelitian ini adalah menemukan dominasi Faktor - Faktor Pendorong Penyebab Terjadinya Kemacetan di Kawasan Sukun Banyumanik Kota Semarang.

\section{METODOLOGI PENELITIAN}

Pada dasarnya penelitian ini bertujuan untuk menemukan faktor-faktor pendorong penyebab kemacetan di kawasan Sukun Banyumanik Semarang. Guna mencapai tujuan dan hasil yang diharapkan, penelitian ini menggunakan pendekatan deduktif kuantitatif rasionalistik. Dimana ilmu adalah berasal dari pemahaman intelektual kita yang dibangun atas kemampuan argumentasi secara logis dengan data-data yang ada. Dengan adanya penekanan empiris dan mampu berargumentasi secara logis dan perlu dibantu dengan data yang relevan, agar produk ilmu yang melandaskan diri pada rasionalisme memang ilmu, bukan fiksi.

Penelitian ini dimulai dengan tahap sebagai berikut:

1. Identifikasi Eksisting Faktor-Faktor Pendorong Penyebab Kemacetan di Sukun Banyumanik;

2. Analisis Faktor-Faktor Pendorong Penyebab Kemacetan di Sukun Banyumanik.

Data yang digunakan dalam penelitian ini berupa data primer dan data sekunder yang diperoleh melalui pengumpulan data dengan traffic counting, quisioner dan pengamatan serta identifikasi secara visual tentang kondisi exsisting dilokasi penelitian. Teknik analisis yang digunakan untuk melakukan analisis dalam penelitian ini adalah menggunakan teknik analisis faktor dan analisis transportasi untuk mengetahui faktor-faktor pendorong penyebab kemacetan 
Transportasi merupakan suatu proses perpindahan orang maupun barang dari satu tempat ke tempat lain dengan menggunakan sistem tertentu untuk maksud dan tujuan tertentu (Timboeleng A. James, Kaseke H. Oscar, 2015).

Fungsi transportasi yaitu menghubungkan orang dengan tata guna lahan, memberikan fungsi tempat dan waktu untuk kebutuhan komoditi. Adaya transportasi diharapkan dapat mempermudah perpindahan barang mapun manusia dari satu tempat ke tempat lain yang memiliki tata guna lahan yang tidak sama. Misalnya dari suatu permukiman ke tempat bekerja, dari rumah ke sekolah dan lain sebagainya (Timboeleng A. James, Kaseke H. Oscar, 2015).

Sistem transportasi dinilai baik apabila waktu perjalanan tidak terlalu lama dan tepat waktu, tidak terjadi arus lalu lintas yang tersendat atau macet, pelayanan yang memadai, dan aman dari bahaya kecelakaan. Kondisi tersebut sangat dipengaruhi oleh beberapa faktor komponen transportasi seperti kondisi sarana dan prasarana jalan, kondisi kendaraan dan kesiapan mental pengendara dan penggguna fasilitas transportasi tersebut (Lubis Aulia Yusuf, 2016).

Perkembangan struktur jaringan jalan cenderung membentuk kawasan yang berkembang dan strategis sebagai kawasan yang paling aksesibel (Tamin, 2000). Hal ini menyebabkan pergerakan memusat ke kawasan tersebut yang ditandai dengan besarnya volume kendaraan baik bertujuan melakukan kegiatan di kawasan tersebut maupun hanya melewati. (Tamin, 2000).

Aktivitas-aktivitas yang membutuhkan pergerakan tentunya membutuhkan ruang dan waktu, oleh sebab itu pergerakan mempunyai asal dan tujuan tertentu yang akhirnya menimbulkan bangkitan dan tarikan lalu-lintas. Dengan demikian pemusatan aktivitas komersil seperti perdagangan dan jasa disatu sisi akan berdampak pada ketidakseimbangan bangkitan dan tarikan pergerakan yang akan menyebabkan gangguan kemacetan lalu-lintas pada suatu kawasan.

Beberapa faktor utama yang mempengaruhi transportasi kota di indonesia yaitu :

a. Faktor kegiatan kota baik dalam kegiatan sosial, ekonomi dan kebudayaan.

b. Faktor jaringan transportasi kota yaitu sarana dan prasarana transportasi.

c. Faktor pergerakan atau arus lalu lintas transportasi.

d. Faktor kelembagaaan yang mengatur lalu lintas.

e. Faktor regional daerah yaitu arua lalu lintas yang berasal dari daerah pinggiran kota maupun kota -kota kabupaten sekitarnya. 
Arus lalu lintas terjadi akibat suatu proses pemenuhan kebutuhan hidup. Menurut Jones (1977) arus lalu lintas dapat terjadi akibat dari beberapa hal, diantaranya sebagai berikut:

1. Pengambilan keputusan untuk melakukan perjalanan.

2. Kemana perjalanan akan dituju.

3. Dengan alat angkut apa perjalan akan dilakukan.

4. Lewat rute mana perjalan akan dilakukan.

5. Kapan perjalan itu akan dilakukan.

Warpani (1981) berpendapat bahwa hampir setiap orang menginginkan bergerak dengan cepat, aman, nyaman, dan mudah. Namun, di sisi lain terdapat banyak orang yang sama-sama melakukan perpindahan dari satu tempat ke tujuan yang sama (Handajani Mudjiastuti, R. Faisal Akbar, 2010).

Hal ini terjadi karena di dalamnya terdapat faktor manusia, ekonomi, fisik, sarana dan prasarana, administrasi, dan lain sebagainya. Permasalahan transportasi dapat dipisahkan dengan hal-hal sebagai berikut:

a) Tata Guna Lahan

Warpani (1981) berpendapat bahwa tata guna lahan erat kaitannya dengan jumlah bangkitan perjalanan, sehingga untuk mempelajari bangkitan perjalanan, kita harus mengetahui jenis tata guna lahan yang akan diteliti terlebih dahulu. Tata guna lahan memperlihatkan bahwa kegiatan yang ada dan menempati petak lokasi yang bersangkutan. Setiap petak dapat menggambarkan tiga ukuran dasar yaitu jenis kegiatan yang terjadi, intensitas penggunaan, dan hubungan antar guna lahan.

b) Penduduk

Faktor utama yang menjadi permasalahan transportasi adalah penduduk. Dalam semua lingkup perencanaan, penduduk tidak dapat diabaikan (Warpani, 1990). Pasalnya, Pelaku utama dari pergerakan di jalan adalah manusia. Pengetahuan tentang tingkah laku dan jumlah pertumbuhan penduduk merupakan hal utama bagi proses perencanaan transportasi.

c) Keadaan Sosial Ekonomi

Pergerakan dan kegiatan orang juga dapat diakibatkan oleh keadaan sosial ekonomi. Mata pencaharian, pendapatan dan kendaraan yang dimiliki dapat memberikan arus lalu lintas transportasi yang dijalani, rute lalu lintas yang diakses, waktu tempuh dan kendaraan yang digunakan. 
Pengertian kemacetan menurut Gito Sugiyanto merupakan kondisi tersendatnya atau berhentinya lalu lintas yang dikarenakan oleh jumlah kendaraan yang terlalu banyak dan melebihi kapasitas jalan yang tersedia. Dalam kata lain, kemacetan adalah kondisi kendaraan yang sangat banyak sehingga terjadi penumpukan yang dikarenakan kapasitas jalan tidak sesuai dengan jumlah kendaraan (Lubis Aulia Yusuf, 2016).

Menurut penelitian Administration (2005), terdapat 7 penyebab kemacetan, yaitu:

1. Physical Bottlenecks

Physical Bottlenecks adalah kemacetan yang terjadi karena jumlah kendaraan sudah melewati batas maksimum. Batas tersebut diperoleh dari faktor jalan, persimpangan jalan, dan tata letak jalan.

2. Kecelakaan Lalu Lintas (traffic incident)

Kemacetan kecelakaan lalu lintas yaitu kemacetan yang diakibatkan dari adanya insiden atau kecelakaan di jalur perjalanan. Kecelakaan tersebut mengakibatkan kemacetan karena kendaraan yang terlibat kecelakaan tersebut menutup sebagian ruas jalan. Hal inilah yang menyebabkan adanya kemacetan karena perlu waktu dalam mengevakuasi kendaraan yang terlibat kecelakaan.

3. Area Pekerjaan (work zone)

Kemacetan ini merupakan kemacetan yang dikarenakan oleh adanya aktivitas kontruksi pada jalan. Aktivitas tersebut akan mengakibatkan perubahaan kondisi lingkungan jalan. Perubahan-perubahan kondisi lingkungan jalan tersebut seperti ketinggian jalan ataupun lebar jalan yang berbeda, pengalihan ataupun penutupan jalan, dan lain sebagainya.

4. Cuaca yang Buruk (bad weather)

Kondisi cuaca juga dapat mengakibatkan perubahan cara mengemudi seorang pengendara kendaraan, sehingga hal tersebut dapat mempengaruhi arus lalu lintas. Misalnya kondisi cuaca dalam keadaan hujan lebat dapat mengurangi jarak penglihatan pengemudi, sehingga banyak pengemudi menurunkan kecepatan dalam berkendara.

\section{Alat Pengatur Lalu Lintas (poor signal timing)}

Kemacetan yang dikarenakan alat pengatur lalu lintas merupakan pengaturan lalu lintas yang bersifat kaku dan tidak mengikuti tinggi rendahnya arus lalu lintas. Selain lampu merah, jalur kereta api juga mempengaruhi tingkat kepadatan jalan, sehingga jalur kereta api yang memotong jalan harus seoptimal mungkin. 
Kemacetan terjadi jika arus lalu lintas mendekati kapasitas. Kemacetan semakin meningkat apabila arus begitu besarnya sehingga kendaraan sangat berdekatan satu sama lain. Kemacetan total apabila kendaraan harus berhenti atau bergerak lambat ( Ofyar Z Tamin, 2000).

Dalam menghitung tingkat kemacetan pada suatu ruas jalan, ditentukan dengan beberapa karakteristik arus lalu lintas yang terdiri dari :

1. Arus lalu lintas jalan, yaitu jumlah kendaraan bermotor yang melalui titik tertentu persatuan waktu, dinyatakan dalam kendaraan perjam atau smp/jam (MKJI, 1997). Arus lalu lintas perkotaan terbagi menjadi empat (4) jenis, yaitu Kendaraan ringan / Light vehicle (LV), Kendaraan berat/ Heave Vehicle (HV), Sepeda Motor/ Motor cycle (MC), Kendaraan Tidak Bermotor / Un Motorized (UM).

2. Volume Lalu lintas Volume lalu lintas menunjukkan jumlah kendaraan yang melintasi suatu titik pengamatan dalam satu satuan waktu.

3. Kapasitas Jalan, yaitu jumlah kendaraan maksimum yang dapat melewati suatu jalan pada jalur jalan selama 1 jam dengan kondisi serta arus lalu lintas tertentu.

4. Derajat Kejenuhan (DS) yang didefenisikan sebagai rasio arus lalu lintas terhadap kapasitas, yang digunakan sebagai faktor utama dalam penentuan tingkat kinerja simpang dan segmen jalan. Nilai DS menunjukkan apakah segmen jalan tersebut mempunyai masalah kapasitas atau tidak.

5. Hambatan Samping, yaitu dampak terhadap kinerja lalu lintas dari aktifitas samping segmen jalan. Banyaknya aktifitas samping jalan sering menimbulkan berbagai konflik yang sagat besar pengaruhnya terhadap kelancaran lalu lintas.

6. Tingkat Pelayanan Jalan, yaitu suatu ukuran yang digunakan untuk mengetahui kualitas suatu ruas jalan tertentu dalam melayani arus lalu lintas yang melewatinya (Warpani, (2002)

\section{PEMBAHASAN DAN HASIL}

Ibukota provinsi Jawa Tengah yaitu Semarang termasuk satu dari sekian banyaknya kota-kota besar yang ada di Indonesia. Titik temu dua jalur transportasi penting di pulau jawa yaitu jalur pantura dan jalur selatan Jawa berada di Semarang. Laju pertumbuhan jumlah kendaraan yang sangat banyak dan tidak sepadan dengan pertumbuhan jalan menjadi satu permasalahan kemacetan lalu lintas yang tidak bisa dihindarkan (Nugraha Dedi, Sugito, Ispriyanti DwI, 2013). Kota Semarang memiliki jumlah penduduk sebesar 
1.434.025 jiwa $(69,30 \%$ adalah usia produktif). Hal ini dikarenakan dari perkembangan ekonomi masyarakat yang menyebabkan terus meningkatnya kepemilikan kendaraan bermotor. Fenomena tersebut memiliki imbas pada tingkat mobilitas atau pergerakan penduduk Kota Semarang dalam memenuhi kebutuhan hidup (Handajani Mudjiastuti, R. Faisal Akbar, 2010).

Transportasi darat sangat mendominasi dalam hal sitem transportasi di Kota Semarang. Seiring dengan semakin bertambahnya jumlah penduduk yang sangat pesat dan pertumbuhan penduduk menyebabkan munculnya berbagai kegiatan usaha yang berkembang di Kota Semarang seperti kegiatan perdagangan jasa, industri, pariwisata dan lainnya, hal ini berdampak dengan semakin tingginya aktivitas kegiatan transportasi yang ada di Kota Semarang. Kondisi ini menjadi dampak dari pesatnya pertumbuhan penduduk dan pertumbuhan ekonomi.

Kawasan Sukun berada di Jalan Setiabudi yang berfungsi sebagai jalan Arteri Sekunder. Adanya terminal bayangan sebagai titik kumpul penumpang dan ngetem nya kendaraan umum membuat arus volume lalu lintas meningkat dan kepadatan tinggi, ditambah dengan aktivitas perdagangan jasa berupa Mall Swalayan ADA pada ruas jalan Setia Budi membuat kondisi permasalahan lalu lintas semakin kompleks, hal ini karena posisi Kawasan Sukun yang juga berada di persimpangan (persimpangan jalan Tol dan mengakibatkan terjadinya masalah lalu-lintas seperti kemacetan lalu-lintas pada jam-jam sibuk pagi, siang dan sore hari).

\section{A. Identifikasi Faktor-Faktor Pendorong Penyebab Terjadinya Kemacetan di Kawasan Sukun Banyumanik Kota Semarang.}

Berdasarkan Identifikasi Eksisting Faktor-Faktor Pendorong Penyebab Kemacetan di Sukun Banyumanik didapat beberapa kondisi yang berpotensi menimbulkan berbagai permasalahan lalu lintas yaitu :

a. Adanya percampuran moda transportasi yaitu lalu lintas lokal, regional dan menerus dengan akses menuju pusat kota dan jalan Tol.

b. Berdasar geometrik jalan di kawasan Sukun, terdapat Adanya persimpangan jalan, baik simpang bersinyal maupun tak bersinyal dan terdapat beberapa ruas jalan yang marging traffic (pertemuan dua lengan arus menjadi satu).

c. Penggunaan lahan yang cukup kompleks yaitu adanya on site activity (Swalayan ADA, Terminal Bayangan, Soto Bangkong, Batik Jayakarta). Kondisi tersebut berdampak 
pada tingginya aktivitas hambatan samping yang terdiri dari pejalan kaki, kendaraan keluar dan masuk ke sisi jalan dan kendaraan yang parkir on street.

\section{B. Analisis Faktor-Faktor Pendorong Penyebab Terjadinya Kemacetan di Kawasan} Sukun Banyumanik Kota Semarang.

\section{Analisis faktor pendorong penyebab kemacetan berdasarkan perhitungan analisis Faktor}

Urutan dominasi Faktor - faktor yang pendorong penyebab terjadinya kemacetan adalah:

1. Faktor Terminal Bayangan

2. Faktor Pasar Swalayan ADA

3. Faktor Soto Bangkong

4. Faktor Batik Jayakarta

Faktor-faktor tersebut didapat berdasarkan hasil perhitungan analisis faktor dengan nilai KMO masing-masing faktor adalah sebagai berikut :

1. Nilai KMO untuk analisis faktor terminal bayangan sukun adalah 0,661 yang artinya nilai KMO >0,5 dengan signifikansi $<0,05$;

2. Nilai KMO untuk analisis faktor pasar swalayan ADA banyumanik adalah 0,541 yang artinya nilai $\mathrm{KMO}>0,5$ dengan signifikansi $<0,05$;

3. Nilai KMO untuk analisis faktor perdagangan jasa soto bangkong adalah 0,514 yang artinya nilai $\mathrm{KMO}>0,5$ dengan signifikansi $<0,05$;

4. Nilai KMO untuk analisis faktor Perdagangan Jasa Batik Jayakarta adalah 0,477 yang artinya nilai $\mathrm{KMO}<0,5$ dengan signifikansi $>0,05$.

\section{Analisis faktor pendorong penyebab kemacetan berdasarkan perhitungan analisis transportasi}

Berdasarkan hasil perhitungan dari beberapa skenario analisis, semua variable faktor faktor pendorong mempunyai dampak dan kontribusi terhadap kemacetan pada poros kemacetan di kawasan Sukun Banyumanik. Dengan urutan dominasi faktor pendorong sebagai berikut :

1. On Site Activity Terminal Bayangan, dengan ITP (Indek Tingkat Pelayanan) sebesar 0,78, dimana nilai ini masuk dalam tingkat pelayanan $\mathrm{C}$ dengan karakteristik Arus stabil, kecepatan dapat dikontrol oleh lalu lintas; 
2. Parkir On Street, dengan ITP (Indek Tingkat Pelayanan) sebesar 0,80, dimana nilai ini masuk dalam tingkat pelayanan D dengan karakteristik Arus mulai tidak stabil, kecepatan rendah dan berbeda-beda, volume mendekati kapasitas;

3. On Site Activity Swalayan ADA, dengan ITP (Indek Tingkat Pelayanan) sebesar 0,80, dimana nilai ini masuk dalam tingkat pelayanan D dengan karakteristik Arus mulai tidak stabil, kecepatan rendah dan berbeda-beda, volume mendekati kapasitas;

4. On Site Activity Soto Bangkong, dengan ITP (Indek Tingkat Pelayanan) sebesar 0,80, dimana nilai ini masuk dalam tingkat pelayanan D dengan karakteristik Arus mulai tidak stabil, kecepatan rendah dan berbeda-beda, volume mendekati kapasitas;

5. On Site Activity Batik Jayakarta, dengan ITP (Indek Tingkat Pelayanan) sebesar 0,80, dimana nilai ini masuk dalam tingkat pelayanan D dengan karakteristik Arus mulai tidak stabil, kecepatan rendah dan berbeda-beda, volume mendekati kapasitas;

6. Pejalan Kaki, dengan ITP (Indek Tingkat Pelayanan) sebesar 0,80, dimana nilai ini masuk dalam tingkat pelayanan D dengan karakteristik Arus mulai tidak stabil, kecepatan rendah dan berbeda-beda, volume mendekati kapasitas;

7. Kendaraan Keluar Masuk Simpang, dengan ITP (Indek Tingkat Pelayanan) sebesar 0,80, dimana nilai ini masuk dalam tingkat pelayanan $\mathrm{D}$ dengan karakteristik Arus mulai tidak stabil, kecepatan rendah dan berbeda-beda, volume mendekati kapasitas.

\section{KESIMPULAN dan REKOMENDASI}

\section{A. Kesimpulan}

Dari analisis yang dilakukan, Faktor-faktor pendorong penyebab terjadinya kemacetan di kawasan Sukun Banyumanik Kota Semarang adalah adanya percampuran moda transportasi yaitu lalu lintas lokal, regional dan menerus dengan akses menuju pusat kota dan jalan Tol yang menyebabkan tingginya volume kendaraan dan berdampak pada tingginya kapasitas jalan. Penggunaan lahan yang cukup kompleks yaitu adanya on site activity (Swalayan ADA, Terminal Bayangan, Soto Bangkong, Batik Jayakarta). Kondisi tersebut berdampak pada tingginya aktivitas hambatan samping yang terdiri dari pejalan kaki, kendaraan keluar dan masuk ke sisi jalan dan kendaraan yang parkir on street.

\section{B. Rekomendasi}

Berdasarkan kesimpulan diatas, maka perlu diambil langkah-langkah untuk mendapatkan ruang jalan yang optimal serta pengelolaan jalan secara efektif dan efisien 
sebagai upaya untuk mengatasi permasalahan lalu lintas yang terjadi. Langkah-langkah tersebut antara lain :

1. Melihat besarnya volume kendaraan berat (HV) yang melintasi kawasan Sukun, dimana kondisi tersebut sangat berpotensi terjadinya mix traffic (percampuran lalu lintas) yang menyebabkan rendahnya tingkat pelayanan jalan. Berdasarkan kondisi tersebut maka perlu dilakukan sebuah pengendalian arus lalu lintas dengan melakukan pengaturan waktu, dimana pada jam-jam tertentu (jam puncak), kendaraan tersebut dilarang melewati kawasan Sukun.

2. Penambahan median jalan sesuai dengan pembagian jalur, baik pada poros kemacetan area 1 maupun pada poros kemacetan area 2. Dimana kondisi ini dimaksudkan untuk mengurangi jumlah kendaraan/pemakai jalan yang memotong jalan menuju on site activity, baik Swalayan ADA, terminal bayangan, Soto Bangkong maupun Batik Jayakarta;

3. Untuk para pejalan kaki yang menyeberang, perlu dibuatkan jembatan penyeberangan disekitar lokasi poros kemacetan 2;

4. Pelarangan parkir disepanjang jalan mulai dari traffic light depan pom bensin Sukun sampai ujung Soto Bangkong;

5. Penegakan disiplin lalu lintas terutama bagi angkutan umum agar berhenti/menaik turunkan penumpang dan barang pada tempat pemberhentian/halte.

\section{DAFTAR PUSTAKA}

Ekawati Niken Natalia, Soeaidy Saleh Mochammad, Ribawanto Heru. (2014). Kajian Dampak Pengembangan Pembangunan Kota Malang Terhadap Kemacetan Lalu Lintas (Studi Pada Dinas Perhubungan Kota Malang). Jurnal Administrasi Publik (JAP). 2(1), 129-133.

Handajani Mudjiastuti, R. Faisal Akbar. (2010). Analisis Panjang Perjalanan Dan Kerakteristik Pengguna Kendaraan Bermotor (Studi Kasus Kecamatan Banyumanik Semarang). Jurnal Magister Teknik Sipil.

Julianto, Eko Nugroho. (2007). “Analisis kinerja simpang bersinyal simpang bangkong dan simpang milo semarang berdasarkan konsumsi bahan bakar minyak". Tesis Jurusan Teknik Sipil, Universitas Diponegoro, Semarang.

Khisty, C. Jotin, (2005). Dasar dasar Rekayasa Transportasi. Jakarta: Fidel Miro 
Lubis Aulia Yusuf. (2016). Analisis Biaya Kemacetan Kendaraan Di Jalan Setiabudi (Studi Kasus Depan Sekolah Yayasan Pendidikan Shafiyyatul Amaliyyah) (Ypsa). Jurnal Warta.

Nugraha Dedi, Sugito, Ispriyanti Dwi. (2013). Penentuan Model Sistem Antrean Kendaraan Di Gerbang Tol Banyumanik Semarang. Jurnal GAUSSIA. 2 (2).

Siswanto Agus, Putro Saptono, Tjahyono Heri. (2012). Kajian Tingkat Kemacetan Lalulintas Pada Jaringan Jalan Yang Menjadi Akses Masuk Kota Semarang. Jurnal Jurusan Geografi.

Tamin, Ofyar Z. (2000). "Perencanaan dan Pemodelan Transportasi”. Bandung: Penerbit ITB.

Timboeleng A. James, Kaseke H. Oscar. (2015). Analisa Biaya Transportasi Angkutan Umum Dalam Kota Manado Akibat Kemacetan Lalu Lintas (Studi Kasus: Angkutan Umum Trayek Pusat Kota 45-Malalayang). Jurnal Sipil Statik. 3 (1).

Warpani, Swarjoko. (1990). “Merencanakan Sistem Perangkutan”. Bandung: Penerbit ITB.

Wikrama, Jaya. (2011). “Analisis Kinerja Simpang Bersinyal (Studi Kasus Jalan Teuku Umar Barat - Jalan Gunung Salak)”. Jurnal Ilmiah Teknik Sipil Vol. 15, No. 1, Januari 2011. 